Supporting Information for:

\title{
Electrochemically Triggered Pore Expansion in Nanoporous Gold Thin Films
}

\author{
Tatiana S. Dorofeeva, Zimple Matharu, Pallavi Daggumati, Erkin Seker* \\ Department of Electrical and Computer Engineering, University of California - Davis, \\ Davis, CA 95616, USA \\ *Corresponding author: eseker@ucdavis.edu
}




\section{Sample Preparation}

The glass cover slips used as substrates, were cleaned by immersion in a piranha solution for 7 minutes, rinsed in deionized (DI) water, and dried under nitrogen flow. The samples were subsequently loaded into a sputtering machine (Kurt J. Lesker) for thin film deposition. Initially, $120 \mathrm{~nm}$ of chrome (to promote adhesion between glass and gold) was sputtered at $300 \mathrm{~W}$,

followed by $80 \mathrm{~nm}$ of seed gold at $400 \mathrm{~W}$, finally $500 \mathrm{~nm}$ of silver and gold were co-sputtered at $100 \mathrm{~W}$ and $200 \mathrm{~W}$ respectively. All depositions were performed under argon atmosphere at 10 mTorr. Elemental compositions of the samples were ascertained with energy dispersive X-ray spectroscopy (Oxford INCA Energy-EDS), the resulting gold and silver content of the films was 36\% Au and 64\% Ag by atomic \%. Deposited samples were dealloyed in 70\% nitric acid for 15 minutes at $55{ }^{\circ} \mathrm{C}$ to produce the $\mathrm{np}-\mathrm{Au}$ films. The dealloying process typically leads to $3-5 \%$ residual silver in the final $\mathrm{np}-\mathrm{Au}$ film. To completely remove traces of nitric acid after the dealloying step, samples were rinsed several times and stored in DI water. After 2 days, samples were removed from water, dried with nitrogen gun, and stored in ambient conditions until the electrochemical etching experiments.

\section{Electrochemical Etching and Measurement Setup}

Coverslips were cut into $6 \times 24 \mathrm{~mm}$ samples. Electrochemical etching was performed by immersing part of the np-Au sample in a mixture of hydrochloric acid and water. Potentiostat (PalmSens) in a 2-electrode configuration was used to apply positive voltage to the $\mathrm{np}-\mathrm{Au}$ sample, while platinum wire served as an anode (Figure S1A). Cyclic voltammetry was used to determine the oxidation range. We observed an oxidation peak with high current at $1.1 \mathrm{~V}$ (Figure S1C), thus all etching experiments were performed at potential of $1.1 \mathrm{~V}$. Substantial etching of np-Au samples was always accompanied by a noticeable color change. 
A

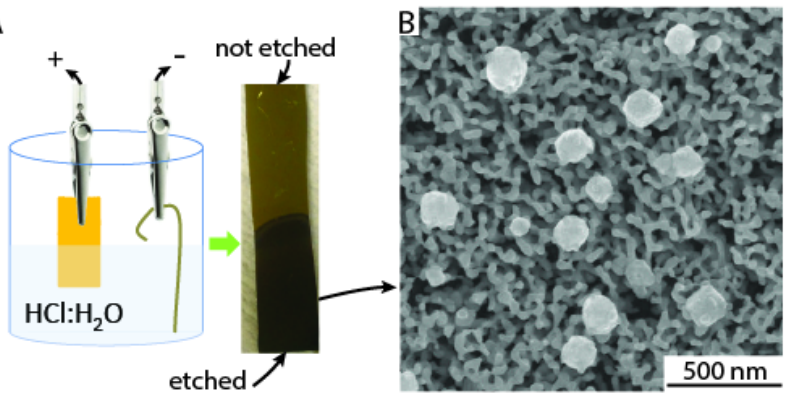

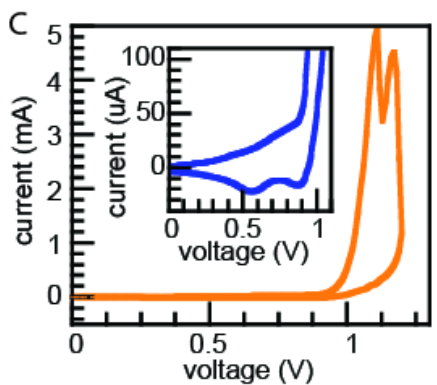

Figure S1. (A) Experimental setup. (B) Nanoparticle residues on the surface after etching process. (C) Cyclic voltammogram

Samples imaged immediately after electrochemical etching revealed the presence of $100-400$ $\mathrm{nm}$ sized particles (Figure S1B). Presence of chlorine was detected via EDS as shown in Table S1. We hypothesized that these particles are the remainder products of the gold-chlorine reaction and therefore should be soluble in water. Thus, after electrochemical etching samples were soaked in copious amounts of water over 24 hours, which led to complete removal of the particles.

Table S1. Elemental analysis of the residual particles following the etch

\begin{tabular}{cccc}
\multicolumn{4}{c}{ EDS analysis (\% composition) } \\
Element & un-etched & etched & etch $+\mathrm{H}_{2} \mathrm{O}$ soak \\
& & & \\
$\mathrm{Cl}$ & $\mathrm{n} / \mathrm{a}$ & 4.41 & $\mathrm{n} / \mathrm{a}$ \\
\hline $\mathrm{Cr}$ & 2.91 & 7.74 & 3.26 \\
\hline $\mathrm{Ag}$ & 3.82 & 6.19 & 3.55 \\
\hline $\mathrm{Au}$ & 93.27 & 81.66 & 93.20
\end{tabular}

\section{Morphological Uniformity}

SEM images obtained by imaging the np-Au sample along the longest dimension in $2-4 \mathrm{~mm}$ steps revealed exceptional morphology uniformity. In Figure S2 the darker region corresponds to the etched area, while the lighter region is from portion not immersed in the liquid (therefore 
not etched). Pore area coverage along the length of the etched section remains constant at approximately 50\%, while it drops slightly at the transition region near $12 \mathrm{~mm}$ mark to $42 \%$ and then to $32 \%$ in the un-etched region.
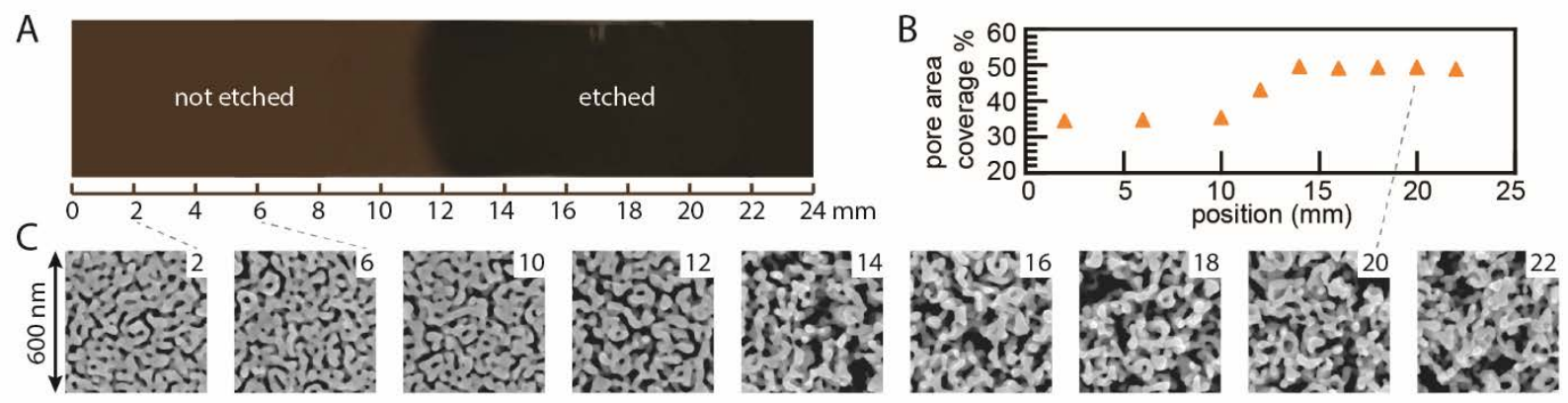

Figure S2. (A) Optical image of the etched sample. (B) Pore area coverage along the sample length extracted from the SEM images along the sample length (C). Test conditions: $V_{\text {on }}=1.1 \mathrm{~V}, V_{\text {off }}=0 \mathrm{~V}, f=1$ $\mathrm{Hz}, t_{\text {etch }}=20 \mathrm{~s}$

\section{Etching at Different Potentials and Concentrations}

Several different concentrations from 1:2 $\left(\mathrm{HCl}: \mathrm{H}_{2} \mathrm{O}\right)$ to $1: 11$ were initially investigated (Figure S3). Under equivalent test conditions $\left(\mathrm{V}_{\text {on }}=1.1 \mathrm{~V}, V_{\text {off }}=0 \mathrm{~V}, t_{\text {etch }}=10 \mathrm{~s}, f=1 \mathrm{~Hz}\right)$, higher concentrations (1:2) resulted in more rapid etching; while lower concentrations (1:11) resulted in less etching. No etching was observed after holding electrode potential at $0 \mathrm{~V}$ for 30 minutes and at voltages below $1.1 \mathrm{~V}$ as shown in Figure S4.
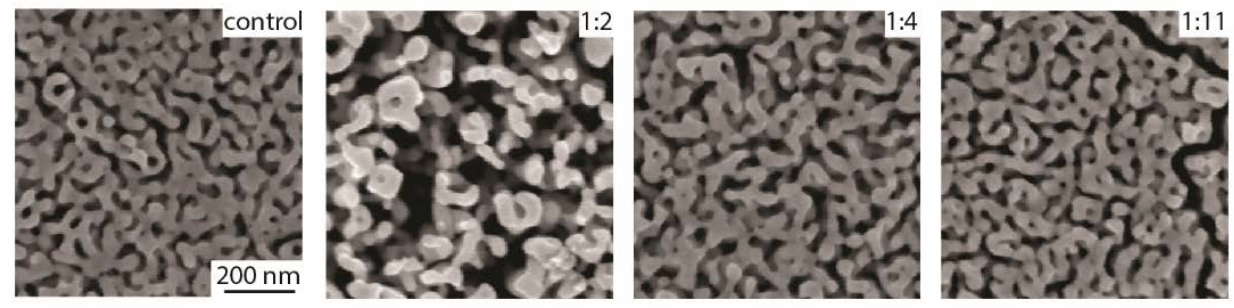

Figure S3. Etching at different $\mathrm{HCl}$ concentrations $V_{\text {on }}=1.1 \mathrm{~V}, V_{\text {off }}=0 \mathrm{~V}, t_{\text {etch }}=10 \mathrm{~s}, f=1 \mathrm{~Hz}$. 

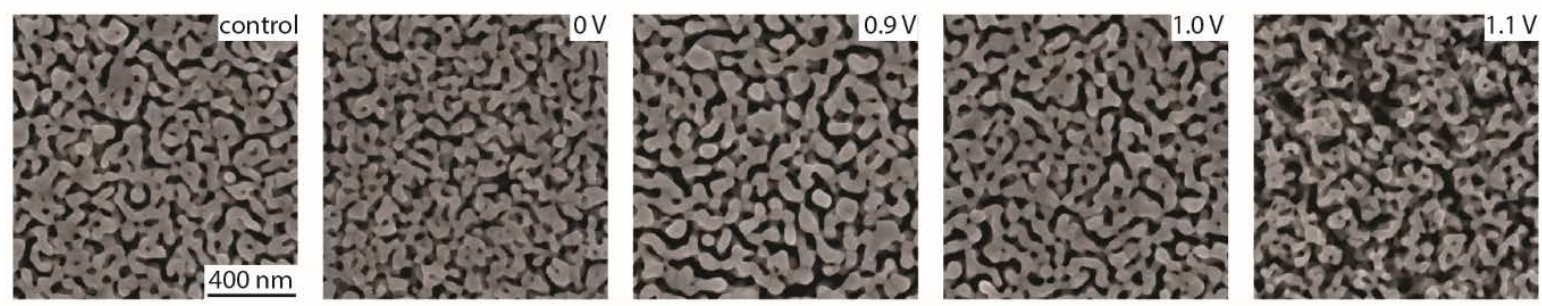

Figure S4. Etching at different $V_{o n}: 0,0.9,1.0$, and $1.1 \mathrm{~V}$. In the $V_{o n}=0 \mathrm{~V}$ case $t_{\text {etch }}=30 \mathrm{~min}$, to demonstrate that no etching occurs. For the remaining cases $V_{\text {off }}=0 \mathrm{~V}, t_{\text {etch }}=10 \mathrm{~s}$, and frequency $=1$ $\mathrm{Hz}$.

\section{Etch at Constant Potential versus Time-Varying Potential}

Comparison of morphologies obtained by time-varying potential (at $f=1 \mathrm{~Hz}$ ) and constant potential etching with equivalent etch time of $20 \mathrm{~s}$ and same voltage levels, did not reveal significant differences as shown in Figure S5.
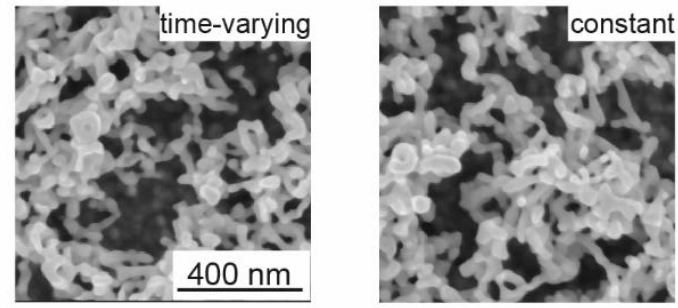

Figure S5. Morphologies obtained by time-varying and constant potential etching. For time-varying $V_{\text {on }}=$ $1.1 \mathrm{~V}, V_{\text {off }}=0 \mathrm{~V}, f=1 \mathrm{~Hz}, t_{\text {etch }}=20 \mathrm{~s}$. For constant potential $V_{\text {on }}=1.1 \mathrm{~V}, t_{\text {etch }}=20 \mathrm{~s}$

\section{Morphology Comparison (Etching vs. Annealing)}

Morphologies obtained through electrochemical etching and thermal annealing are shown in Figure S6. Top and cross-sectional images reveal that two processes for modifying pore morphology result in very different morphological elements. Electrochemical etching maintains small ligament sizes while at the same time enlarging the pores, thus minimally reducing the surface area compared to the starting material. Ligament thinning takes place uniformly throughout the entire film thickness. In the case of thermal annealing both pores and ligaments 
grow, thus significantly reducing the surface area of the original starting material. As films coarsen, ligaments arrange into more columnar structures, as can be seen in the corresponding cross-sectional image.
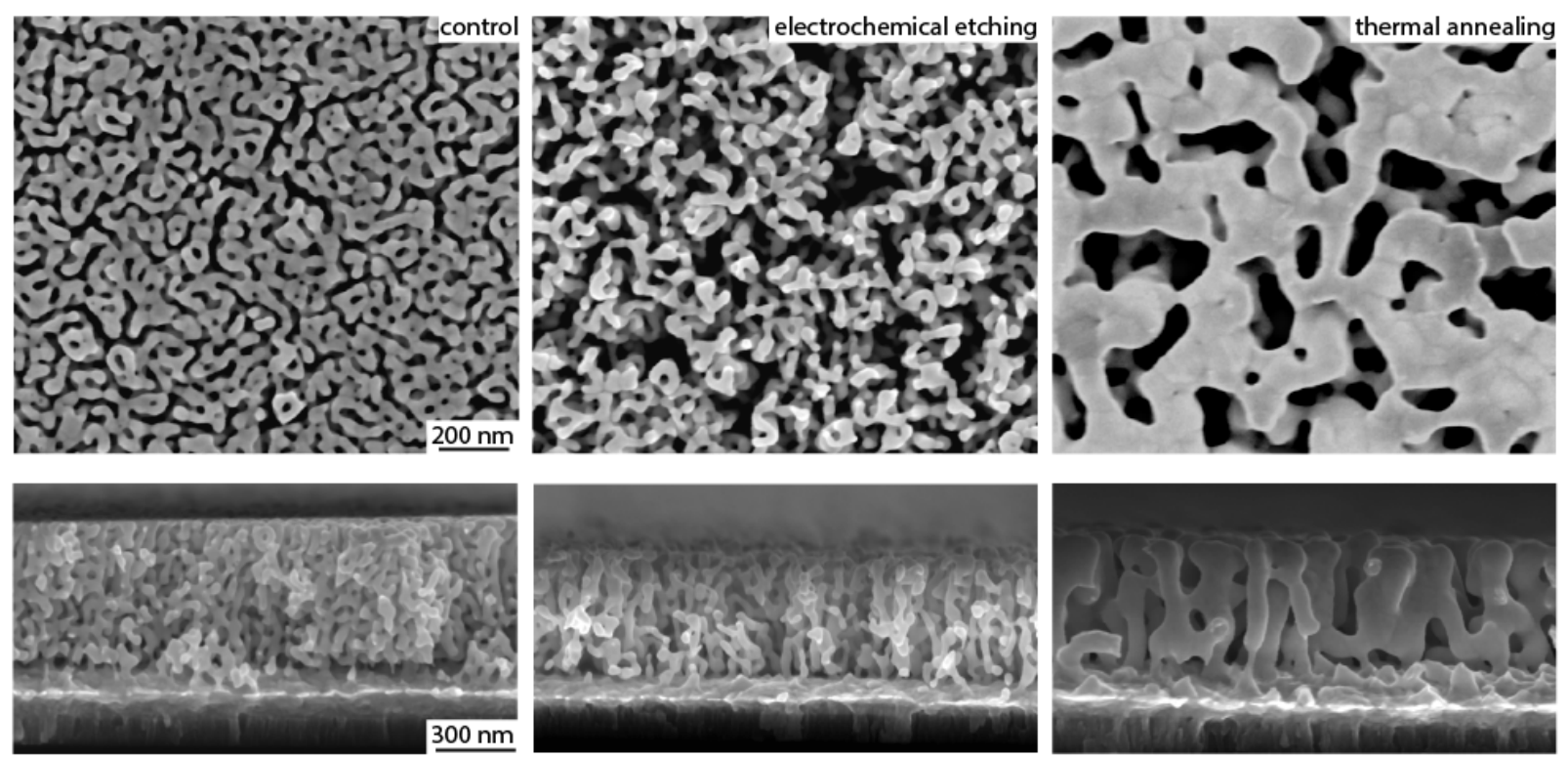

Figure s6. Top and cross-sectional images of $\mathrm{np}-\mathrm{Au}$ samples: (A) not-treated (control), (B) electrochemically-etched, and (C) thermally-annealed. 